\title{
V-Y Advancement Flap: Aesthetic Reconstruction for Auriculotemporal Keloid Excision
}

\author{
Bommie Florence Seo, \\ Hyo Sun Ko, Ho Kwon, \\ Sung-No Jung
}

Department of Plastic and Reconstructive Surgery, Uijeongbu St. Mary's Hospital, College of Medicine, The Catholic

University of Korea, Uijeongbu, Korea

No potential conflict of interest relevant to this article was reported.
Keloid scars are commonly found on the ears. Treatment modalities include compression, intralesional steroid injection, and surgical excision with or without radiotherapy, depending on the size and location of the keloid scar. Excision may be a curative solution, but it always requires the immediate reconstruction of the excised defect. Herein, we report the case of a keloid scar located at the helical base of the auriculotemporal sulcus that was treated by excision and a V-Y temporal advancement flap.

Keywords Ear auricle, Keloid, Surgical flaps

\section{INTRODUCTION}

Keloids are most commonly located in the ears (44.4\%), followed by the thorax (33.3\%), and shoulders (7.4\%) [1]. Keloids, along with hypertrophic scars, are caused by an aberration in the normal wound healing process and inflict great discomfort on the patient [2]. Abnormal scars may cause pain or pruritus, disturb the range of motion, diminish sensation, or cause aesthetic deformities that may lead to significant psychosocial distress. Treatment modalities include compression therapy, cryosurgery, injections (steroids, mitomycin C, 5-fluorouracil, interferon, or platelet-rich plasma [PRP]), surgery, and postoperative radiotherapy, depending on the size and location of the keloid scars [3-6].

Auricle keloids usually are preceded by piercing, surgery, or trauma. Keloids of the ear have the potential to grow aggressively, enveloping the neighboring tissue [7]. Because the auricle is an aesthetically important portion of the facial area, treatment options must be carefully chosen to maintain a normal appearance and prevent deformity. Compression therapy or serial steroid injections

Received: Aug 10, 2017 Revised: Aug 17, 2017 Accepted: Aug 19, 2017 Correspondence: Sung-No Jung Department of Plastic and Reconstructive Surgery, Uijeongbu St. Mary's Hospital, College of Medicine, The Catholic University of Korea, 271 Cheonbo-ro, Uijeongbu 11765, Korea.

E-mail: jsn7190@catholic.ac.kr

Copyright @ 2017 The Korean Society for Aesthetic Plastic Surgery.

This is an Open Access article distributed under the terms of the Creative Commons Attribution Non-Commercial License (http://creativecommons.org/licenses/by-nc/4.0/) which permits unrestricted non-commercial use, distribution, and reproduction in any medium, provided the original work is properly cited. $\quad$ www.e-aaps.org are a less invasive approach, but it is difficult to obtain absolute resolution with these treatments. Excision is the most efficient method of treatment, but it is accompanied by the risk of recurrence, which surgeons constantly combat with various adjuvant therapies, and by the necessity of an immediate reconstruction of the defect, which results from a sufficient resection. In smaller lesions, the defect is usually closed primarily or with the aid of a local flap. Larger lesions require a skin graft or a more intricately designed regional flap. The disadvantage of skin grafts is that they cause color mismatch as well as additional donor morbidity [8].

Ear keloids located near the auriculotemporal sulcus require a reconstruction method that maintains the cephaloauricular angle and prevents blunting of the sulcus. Herein, we report the use of a $\mathrm{V}-\mathrm{Y}$ temporal advancement flap for the excision of a keloid scar.

\section{CASE REPORT}

A 12-year-old female patient presented with a keloid scar on the left ear. The lesion was a rubbery, firm mass with its base at the root of the helix, extending along the auriculotemporal sulcus for its entire length $(3 \mathrm{~cm})$. The lesion was $1.3 \mathrm{~cm}$ wide and $1.2 \mathrm{~cm}$ high (Fig. 1). The scar had developed several months beforehand after the patient sustained a deep abrasion in the area. The patient was scheduled for full excision and flap coverage, as well as postoperative radiation. Sufficient excision of the scar tissue resulted in a defect measuring $1.5 \times 3 \mathrm{~cm}$. To cover the defect, we outlined a V-Y advancement flap in a perpendicular vector. The flap was in a random pattern based on the temporal artery and began above the hairline in order to secure enough tissue to provide tensionless ad- 


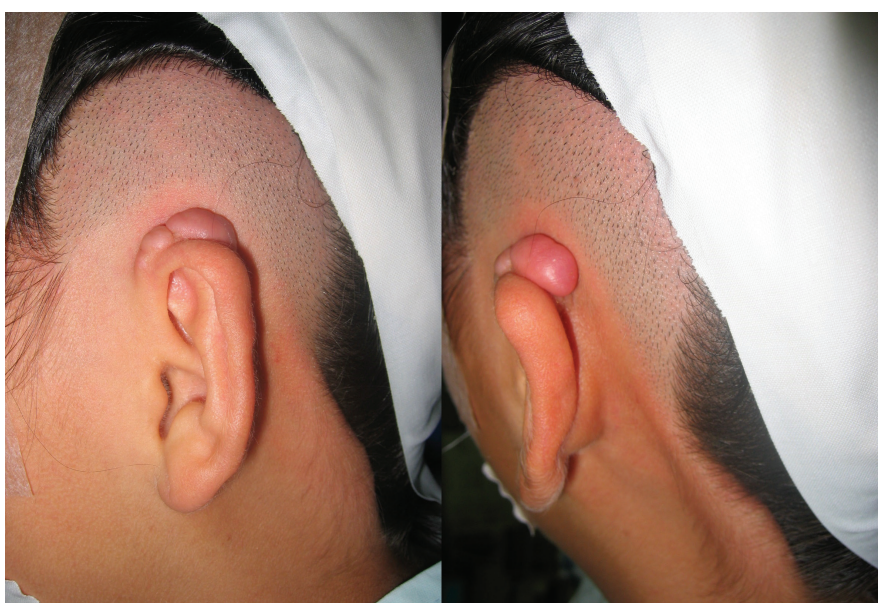

Fig. 1. The 12-year-old female patient with a $3-\mathrm{cm}$ long and $1.3-\mathrm{cm}$ wide keloid scar at the auriculotemporal sulcus.

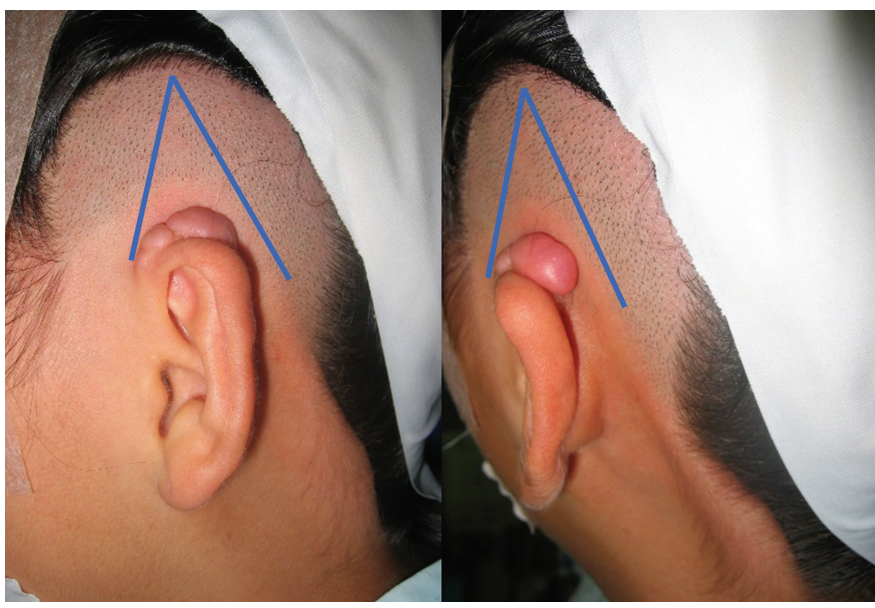

Fig. 2. A schematic drawing of the $V-Y$ advancement flap that was outlined for coverage of the expected defect. Note that the posterior corner of the flap is connected to a skin bridge at the postauricular aspect.

vancement (Fig. 2). The flap was elevated on the suprafascial plane and advanced $1.5 \mathrm{~cm}$ toward the ear. Undermining was kept to a minimum in order to ensure flap survival. A posterior bridge of skin was left at the posterior distal base of the flap connected to the postauricular skin. The flap was completely free of tension. After the viability of all flaps was verified, closure was performed (Fig. 3).

Postoperative radiation was performed for 3 consecutive days beginning on the day of the excision. In total, 1,200 cGy was administered in fractions of $400 \mathrm{cGy}$ per day. There were no complications.

The wounds healed well and with no immediate complications, such as hematoma or skin necrosis. The patient underwent laser depilation in the advanced hairline area. The scars were well hidden along the normal sulcus, and no recurrence was noted at 2 years

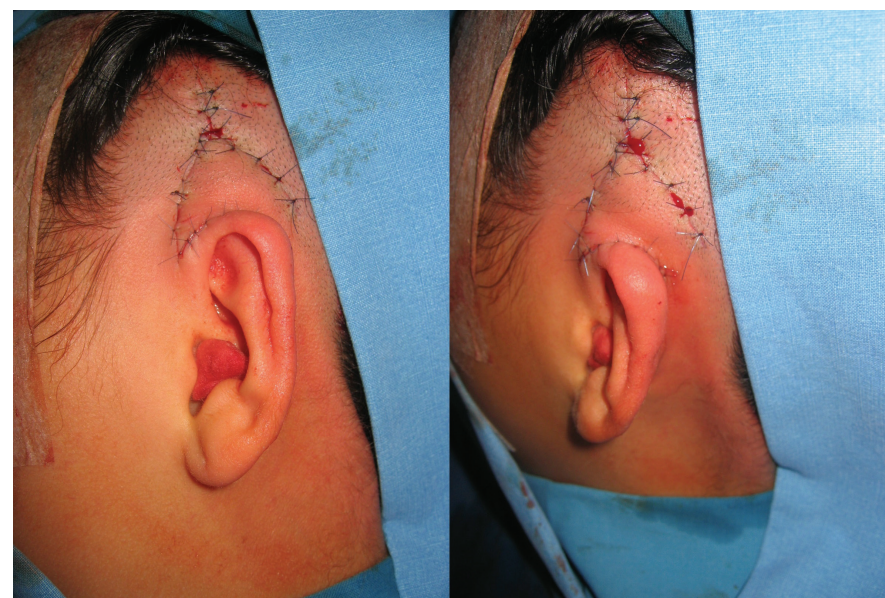

Fig. 3. Immediately after tension-free closure. The flap was closed in a V-Y pattern.

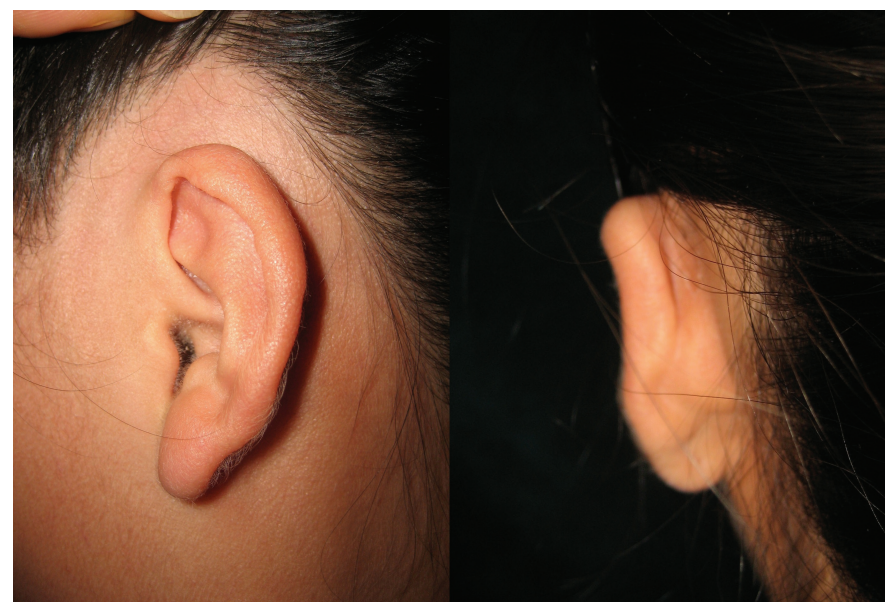

Fig. 4. At 2 years after the operation, no recurrence was observed, and the scars were almost invisible.

after the operation (Fig. 4).

\section{DISCUSSION}

Keloid scars are abnormally proliferative scars that are caused by an aberration in the normal wound healing process [2]. Keloids commonly occur around the ears, usually due to piercings [7]. Curative treatment of keloids is difficult, and a plethora of treatment options has been studied. Treatment modalities include compression therapy, cryosurgery, injections (steroids, mitomycin C, 5-fluorouracil, interferon, or PRP), surgery, and postoperative radiotherapy, depending on the size and location of the keloid scar [3-6]. Studies have found that keloid treatment is most effective when using multiple modalities, but there is still much controversy as to what is the optimal treatment [7]. Surgical excision without adjuvant therapy of the keloids, irrespective of the location, is said to 
have a recurrence rate between $45 \%$ and $100 \%$ [9].

Because of its innate structure and tight-fitting skin coverage, excision of auricle tissue requires meticulous planning of the reconstruction. Extramarginal excision of the keloid is effective, but many reports have found recurrence along the incision lines that are closed under tension. Tension is a challenge in this area because of the anatomical characteristics of the ear. The earlobe is a single noncartilaginous component and has a small amount of soft tissue and skin that can be mobilized, but the helix consists of an intricate scaffold of elastic cartilage that may be easily exposed and lead to deformities and a much tighter, thin layer of subcutaneous tissue and skin. Within the helix, the anterior and posterior surfaces are different. The anterior surface has a skin envelope ranging from 0.8 to $1.2 \mathrm{~mm}$ in thickness and is firmly connected to the perichondrium. The posterior skin is slightly more yielding due to a layer of fat between the cartilage and skin, providing the posterior surface with a cumulative 1.2 to $3.0 \mathrm{~mm}$ of tissue [10].

As a result, surgeons are continually developing excision designs or reconstructive techniques that diminish the tension in the auricle. For helix lesions, small to moderate-sized keloids may be treated with wedge resection, although this inevitably leads to asymmetry of the helical rim. Skin grafts may be applied to fill in the defect under no tension. Nguyen et al. [11] have reported successful results using bilaminar dermal substitutes and delayed epidermal skin grafts. However, skin grafts are commonly accompanied by donor morbidity and color mismatch.

Various studies have introduced the method of intramarginal excision, where the surrounding, autoexpanded native skin is allowed to close without tension. Lee et al. [12] suggested removing the core tissue of the keloid and leaving behind the rind flap to resurface the defect. They reported no recurrence in over $87.5 \%$ of patients, over an average follow-up of 20 months. However, although tension-free closure is possible, the quality of the resulting scar is not guaranteed. Scar infiltration of the overlying skin is sometimes problematic, and it is difficult to elevate an even, physiological layer off the core scar in order to avoid irregularities in the skin contour.

One of the most useful options for reconstruction of helical keloid resection defects are local flaps. Local flaps from the posterior surface of the helix or preauricular and postauricular tissue have been used to treat other causes of helical defects, such as skin malignancies, trauma, and congenital deformities. Chondrocutaneous advancement flaps, V-Y advancement flaps, Z-plasty, S-shaped incisions, rotational flaps, and transpositional flaps have been applied, depending on the size and location of the defect $[13,14]$.

Excision of a keloid scar in the upper helical region or the auriculotemporal area of the ear may also be reconstructed with these flaps. The most important aspect in choosing a method of reconstruction is the ability of the method to provide the most tensionfree coverage. An alternative way to approach this region is by referring to treatment options for cryptotia, a congenital deformity in which the upper pole of the ear is buried under the mastoid skin. The various treatment options for cryptotia all have in common the ability to reconstruct the auriculotemporal sulcus and cover the posterior surface of the helix. Modifications of these options may aid surgeons in choosing the optimal reconstruction method to use in the upper auricular area.

The V-Y advancement flap is a straightforward, random-pattern local flap that is easy to design and simple to perform. For these flaps, the distal inferior margin is defined by the area of excision. The posterior margin, however, is located 1 to $2 \mathrm{~cm}$ posterior to the defect, so that the posterior pedicle is connected to the flap to ensure survival. When Cho and Han [15] introduced application of the V-Y flap to correct cryptotia, his team widely elevated a large $\mathrm{V}$ flap in the temporal area, sparing only the anterior and posterior skin pedicles, resulting in good survival and no cases with compromised circulation. Leaving a bridge of skin at the distal aspect of the flap enables wider dissection beneath the advancing $\mathrm{V}$ portion and therefore lengthier advancement. The wider range of advancement enables the surgeon to remove the keloid en bloc and allows tension-free closure along the margins of the defect.

The V-Y advancement flap does have its limitations. The donor site has scars, and the hairline is advanced with the flap. However, as seen in the postoperative photographs (Fig. 1-4), the scars are barely visible, and the hairline irregularity can be overcome with laser treatment. The benefits greatly outweigh the limitations. Because the neighboring tissue is mobilized, there is almost no color or texture discrepancy. No distant donor site is necessary, meaning that excision and reconstruction are performed in a single surgical window. In patients with long hair, the scar can be completely hidden by the hair. Above all, this method provides tension-free coverage, which is the most important factor to bear in mind when reconstructing a defect as part of keloid treatment.

\section{PATIENT CONSENT}

The patient provided written consent for the use of her images.

\section{REFERENCES}

1. Carmassi M, Eraud J, Gonelli D, et al. Keloid scars: a case series study. Ann Pathol 2015;35:148-53.

2. Seo BF, Lee JY, Jung SN. Models of abnormal scarring. Biomed Res Int 2013;2013:423147.

3. Du G, Zhu J. Ear keloid and clinical research progress. Lin Chung Er Bi Yan Hou Tou Jing Wai Ke Za Zhi 2014;29:770-2.

4. Uppal RS, Khan U, Kakar S, et al. The effects of a single dose of 5-fluorouracil on keloid scars: a clinical trial of timed wound irrigation after extralesional excision. Plast Reconstr Surg 2001;108:1218-24.

5. Sidle DM, Kim H. Keloids: prevention and management. Facial Plast Surg Clin North Am 2011;19:505-15. 
6. Davison SP, Mess S, Kauffman LC, et al. Ineffective treatment of keloids with interferon alpha-2b. Plast Reconstr Surg 2006;117:247-52.

7. Jones ME, McLane J, Adenegan R, et al. Advancing keloid treatment: a novel multimodal approach to ear keloids. Dermatol Surg 2017;43: 1164-9.

8. Kim DY, Kim ES, Eo SR, et al. A surgical approach for earlobe keloid: keloid fillet flap. Plast Reconstr Surg 2004;113:1668-74.

9. Froelich K, Staudenmaier R, Kleinsasser N, et al. Therapy of auricular keloids: review of different treatment modalities and proposal for a therapeutic algorithm. Eur Arch Otorhinolaryngol 2007;264:1497-508.

10. Watson D, Panuganti B. Treating scars in the auricle region. Facial Plast Surg Clin North Am 2017;25:73-81.
11. Nguyen KT, Shikowitz L, Kasabian AK, et al. A novel approach to keloid reconstruction with bilaminar dermal substitute and epidermal skin grafting. Plast Reconstr Surg 2016;138:235-9.

12. Lee Y, Minn KW, Baek RM, et al. A new surgical treatment of keloid: keloid core excision. Ann Plast Surg 2001;46:135-40.

13. Jung SN, Park SH, Hwang DY, et al. V-Y-Z plasty for correcting cryptotia. Br J Oral Maxillofac Surg 2009;47:562-3.

14. Simon F, Celerier C, Garabedian EN, et al. Mastoid fascia kite flap for cryptotia correction. Int J Pediatr Otorhinolaryngol 2016;90:210-3.

15. Cho BC, Han KH. Surgical correction of cryptotia with V-Y advancement of a temporal triangular flap. Plast Reconstr Surg 2005;115:157081. 